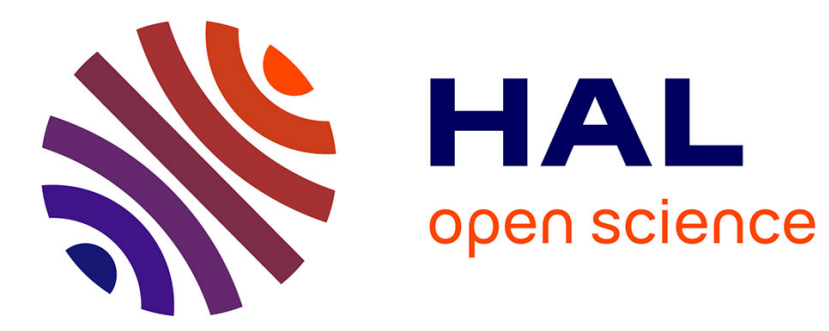

\title{
Synthesis of tolerancing by functional group
}

Jean-Marc Linares, Cédric Anthierens, Jean-Michel Sprauel

\section{To cite this version:}

Jean-Marc Linares, Cédric Anthierens, Jean-Michel Sprauel. Synthesis of tolerancing by functional group. Journal of Manufacturing Systems, 2002, 21 (4), pp.260 - 275. 10.1016/S0278-6125(02)80166-

2. hal-01408879

\section{HAL Id: hal-01408879 \\ https://hal-amu.archives-ouvertes.fr/hal-01408879}

Submitted on 5 Dec 2016

HAL is a multi-disciplinary open access archive for the deposit and dissemination of scientific research documents, whether they are published or not. The documents may come from teaching and research institutions in France or abroad, or from public or private research centers.
L'archive ouverte pluridisciplinaire HAL, est destinée au dépôt et à la diffusion de documents scientifiques de niveau recherche, publiés ou non, émanant des établissements d'enseignement et de recherche français ou étrangers, des laboratoires publics ou privés. 


\section{Synthesis of Tolerancing by Functional Group}

Jean Marc Linares, Cédric Anthierens, and Jean Michel Sprauel, Laboratory EA(MS) ${ }^{2}$, Université de la Méditerranée, IUT d'Aix en Provence, Aix-en-Provence, France

\begin{abstract}
This paper presents a systematic tolerancing method based on a new modeling concept called Functional Group. The tolerancing method is composed of two types of tolerancing: (1) "internal tolerancing" limits assembly errors due to the overabundance of contact points between two surface groups and (2) "external tolerancing" places one surface group next to the other. First, several tolerancing methods are presented from the literature. The small displacement screw (SDS) method is also described because it represents a very important investigation tool. Then the concept of the functional group is proposed for the tolerancing of mechanical systems. Finally, this new systematic method is implemented with an actual example in which functional tolerancing is easily carried out.
\end{abstract}

Keywords: Functional Tolerancing, Tolerancing Modeling, Tolerancing Analysis, Vectorial Tolerancing, Mechanical Design

\section{Introduction}

Worldwide industrial competition obliges the mechanical manufacturing industries to be quickly adaptive. The levels in quality, price, and delivery time desired by customers are becoming more and more significant, and the manufacturing process has to be very reactive to ensure reliability, productivity, and flexibility along with cost control. Companies remain competitive when they control their whole industrialization process by taking into account the product and the manufacturing process. This imposes good coherence between the different functions such as design, manufacturing, and so on.

A method is needed to share information and to ensure coordination between several participants with different goals and different reference systems. The design phase is crucial because at this point about $75 \%$ of the final cost of the product is decided on. Because it is not possible to manufacture any parts perfectly due to the unavoidable inaccuracy of the manufacturing process, it is necessary to develop a computation method and tolerancing method that are coherent. The tolerancing method should share the errors between the different functions suitably.

\section{State of the Art}

Methods of Tolerancing

The geometric data computed by CAD software are considered as surfaces (BRep: boundary representation), and CAD software is based on modeling by features. For the Pro/ENGINEER ${ }^{\circledR}$ software (Parametric Technology Corp. 1994), the feature data are saved in an assembly neutral file and a part neutral file. Each surface is written with parameters in the local coordinate system $\left(\mathrm{O}, \mathrm{e}_{1}, \mathrm{e}_{2}, \mathrm{e}_{3}\right)$ placed in relation with the general coordinate system. Thus, the principal vector and one point of the surface are known. Each surface that needs an intrinsic attribute for its parametric definition gets further data such as radius and angle. Information on the methodical assembly arrangements of the surfaces is also saved in this file. CAD software usually proposes a specific module to help users with dimensional computation. The method based on technologically and topologically related surfaces (TTRS) (Clement, Desrochers, Riviere 1991) is used for a module developed by the CATIA software (Gaunet 2001).

The VSA software of Applied Mechanical Solutions is based on a statistical simulation used to calculate the limits of the tolerance zone. The assembly of surfaces is rebuilt to model the behavior of the whole system. The CE/TOL6 $\sigma$ software of Raytheon operates on assembly issues and provides solutions for tolerancing. This software is associated with Pro/ENGINEER. Numerous works on these topics can be classified according to three main types of approaches.

\section{Vectorial Tolerancing}

This approach is certainly the most widespread today. In this method (Wirtz 1991, Liu and Wilhelm 2001), surfaces are represented by one point and oriented by a vector. Two further vectors are usually used to describe the size and the form of the considered surface.

Several research groups have investigated the writing of tolerancing in a kinematics point of view (Rivest, Fortin, Morel 1994; Sacks and Joskowicz 
1997). Each condition is represented by a set of 14 parameters of the kinematics model.

Several methods are based on the small displacement screw (SDS) method. SDS is the result of many investigations in 3-D metrology. The TTRS method provides a vectorial tolerancing (Gaunet 1993). UPEI (weighted addition of clearance) is a method used to manage free spaces for 3-D mechanisms (Teissandier, Couetard, Gerard 1997). Usually, the SDS only transcribes errors of position and orientation. A new concept of the SDS takes into account the variation of the intrinsic parameters of surfaces (radius of a cylinder, angle of a cone). So these variations are included in the vectorial equations (Ballot and Bourdet 1998).

\section{Space of Feasibility}

The spaces of feasibility are a graphical representation of inequalities defined in the space of parameters by tolerancing (Turner 1993; Bhide, Davidson, Shah 2001). Other methods based on a graphical resolution by simplex are available to model clearances between two surfaces. The result obtained is a hyperspace called "clearance space." This six-dimension hyperspace is composed of six parameters of the SDS. Each assembled part is considered as rigid with no defects on the surface (Giordano et al. 1992). The union and the crossing between these hyperspaces permit the user to solve the assembly problems.

Among numerous investigations on this topic, the computation methods employed in robotics (Jacobian matrix) (Bennis, Pino, Fortin 1999) or computation on polytops with the Minkowski sum (Teissandier, Delos, Couetard 1999) or the method of noninterference space between two parts (Sangho and Kunwoo 1998) are certainly the most used.

\section{Tolerancing by Variation Class}

A proposition for tolerancing is based on the offset zone (Requicha 1983, Wayne and Hanson 1984, Kethara and Wilhelm 2001). Several works show the difference between this concept and the norm, ANSI Y14.5. In the $1990 \mathrm{~s}$, other propositions suggested its evolution (Farmer and Galdman 1986, Etesami 1991). Several investigations are close to the American norm, ANSI Y14.5M (Srinivasan 1993).

This paper presents the results of studies on the functional tolerancing developed to be implemented in CAD software. These advances are based on the

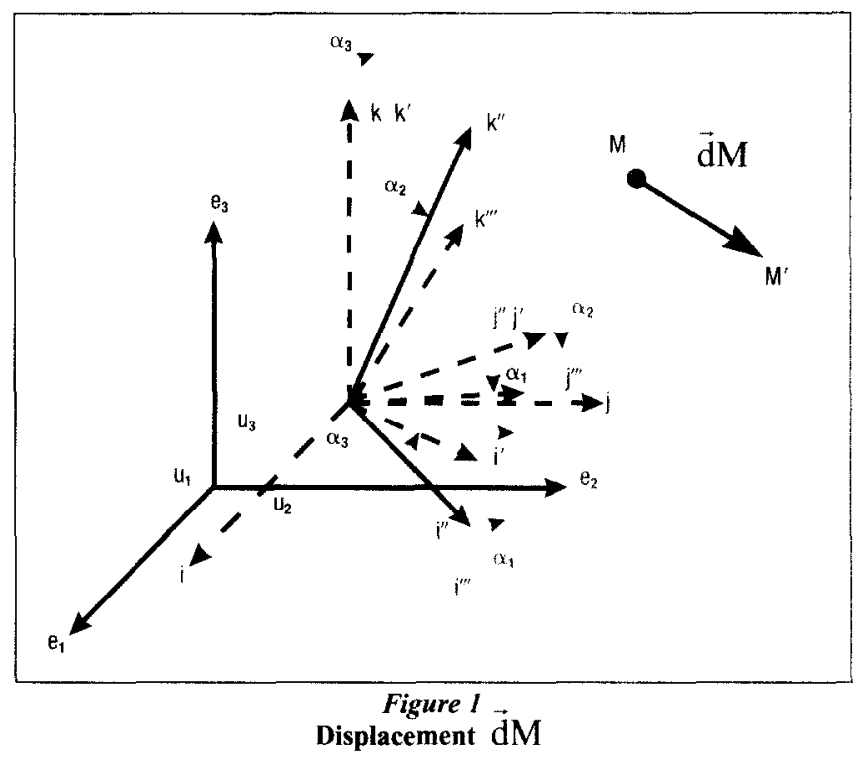

concept of the systematic approach, and the mathematical tool used for modeling is the small displacements screw (SDS). This work can be classified in vectorial tolerancing.

\section{Small Displacements Screw (SDS)}

A mathematical description of the SDS method is presented below. SDS is used to describe the geometric errors of the surfaces. The displacement $\overrightarrow{\mathrm{d}} \mathrm{M}$ of the point $\mathrm{M}$ to the point $\mathrm{M}^{\prime}$ can be defined by the transformation matrix written with homogeneous coordinates in a coordinate system called $\left(\mathrm{O}, \mathrm{e}_{\mathbf{1}}, \mathrm{e}_{\mathbf{2}}\right.$, $\left.e_{3}\right)$. The three angles and one translation vector make the displacement (Figure 1):

$$
\overrightarrow{\mathrm{d}} \mathrm{M}=\left[\begin{array}{cccc}
\mathrm{a}_{11} & \mathrm{a}_{12} & \mathrm{a}_{13} & \mathrm{u}_{1} \\
\mathrm{a}_{21} & \mathrm{a}_{22} & \mathrm{a}_{23} & \mathrm{u}_{2} \\
\mathrm{a}_{31} & \mathrm{a}_{32} & \mathrm{a}_{33} & \mathrm{u}_{3} \\
0 & 0 & 0 & 1
\end{array}\right] \times \overrightarrow{\mathrm{OM}}
$$

with

$$
\begin{aligned}
& \mathrm{a}_{11}=\cos \alpha_{2} \cos \alpha_{3}-1 \\
& \mathrm{a}_{12}=-\cos \alpha_{2} \sin \alpha_{3} \\
& \mathrm{a}_{13}=\sin \alpha_{2} \\
& \mathrm{a}_{21}=\sin \alpha_{3} \cos \alpha_{1}+\sin \alpha_{1} \cos \alpha_{3} \sin \alpha_{2} \\
& \mathrm{a}_{22}=\left(\cos \alpha_{1} \cos \alpha_{3}-\sin \alpha_{1} \sin \alpha_{2} \sin \alpha_{3}\right)-1 \\
& \mathrm{a}_{23}=-\sin \alpha_{1} \cos \alpha_{2} \\
& \mathrm{a}_{31}=\sin \alpha_{1} \sin \alpha_{3}-\cos \alpha_{1} \cos \alpha_{3} \sin \alpha_{2} \\
& \mathrm{a}_{32}=\sin \alpha_{1} \cos \alpha_{3}+\cos \alpha_{1} \sin \alpha_{2} \sin \alpha_{3} \\
& \mathrm{a}_{33}=\cos \alpha_{1} \cos \alpha_{2}-1
\end{aligned}
$$




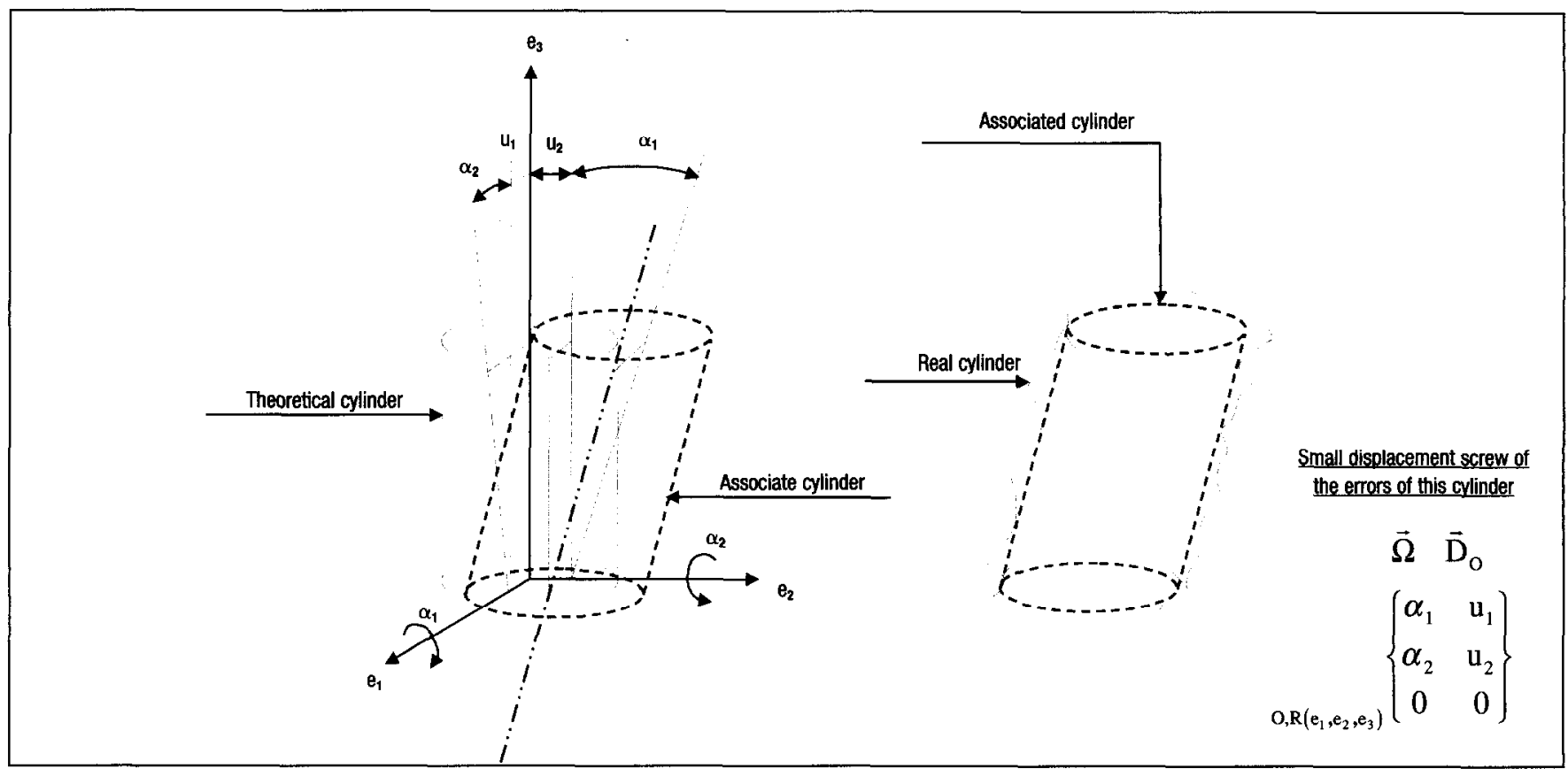

Figure 2

$u_{1}, u_{2}, \alpha_{1}, \alpha_{2}$ Geometrical Errors of the Cylinder

If the three rotations are small enough, the trigonometric functions can be linearized to the first order. Also, the matrix is simplified:

$$
\overrightarrow{\mathrm{d} M}=\left(\begin{array}{cccc}
0 & -\alpha_{3} & \alpha_{2} & \mathrm{u}_{1} \\
\alpha_{3} & 0 & -\alpha_{1} & \mathrm{u}_{2} \\
-\alpha_{2} & \alpha_{1} & 0 & \mathrm{u}_{3} \\
0 & 0 & 0 & 1
\end{array}\right) \times \overrightarrow{\mathrm{OM}} \text { with } \overrightarrow{\mathrm{OM}}\left\{\begin{array}{l}
\mathrm{x} \\
\mathrm{y} \\
\mathrm{z} \\
1
\end{array}\right.
$$

A matrix is developed to the first order. In this case, the multiplication of matrices can be replaced by the sum of the translation vector, $\vec{D}_{0}$, and the vector obtained by the vectorial product between the rotation vector, $\vec{\Omega}$, and the vector of position, $\overrightarrow{\mathrm{OM}}$, as follows:

$$
\overrightarrow{\mathrm{d}} \mathrm{M}=\left\{\begin{array}{l}
\mathrm{u}_{1}-\mathrm{y} \alpha_{3}+\mathrm{z} \alpha_{2} \\
\mathrm{u}_{2}+\mathrm{x} \alpha_{3}-\mathrm{z} \alpha_{1} \\
\mathrm{u}_{3}-\mathrm{x} \alpha_{2}+\mathrm{y} \alpha_{1}
\end{array}=\overrightarrow{\mathrm{D}}_{\mathrm{O}}+\vec{\Omega} \wedge \overrightarrow{\mathrm{OM}}\right.
$$

The SDS is composed of both vectors (translation, $\overrightarrow{\mathrm{D}}_{\mathrm{O}}$, and rotation, $\vec{\Omega}$ ):

$$
\begin{aligned}
& \vec{\Omega} \overrightarrow{\mathrm{D}}_{\mathrm{O}} \\
& \left\{\begin{array}{ll}
\alpha_{1} & \mathrm{u}_{1} \\
\alpha_{2} & \mathrm{u}_{2} \\
\alpha_{3} & \mathrm{u}_{3}
\end{array}\right\}
\end{aligned}
$$

This concept was created in the 1970s (Bourdet and Clement 1988). In this work, SDS is used to represent

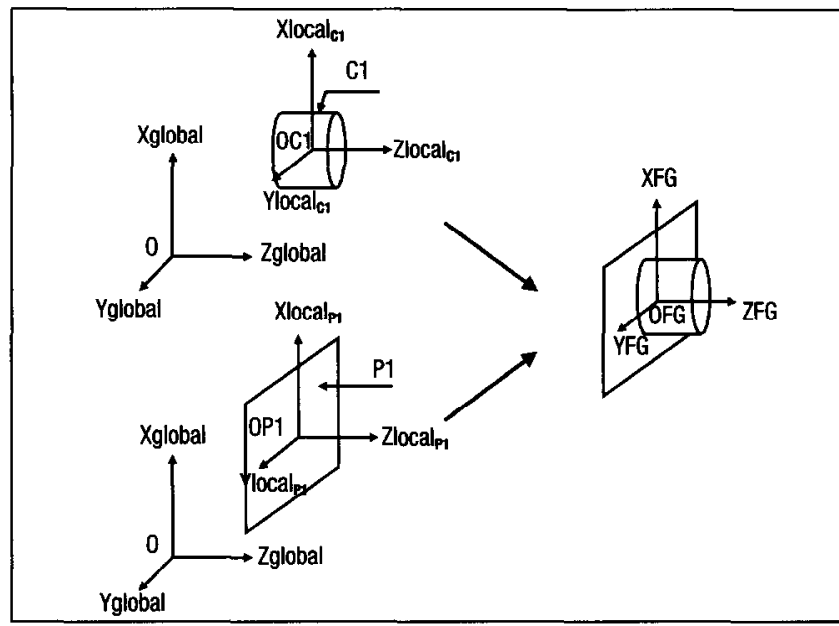

Figure 3

Coordinate Systems

the surface errors (Figure 2). The spatial representation of the surface defects is easily permitted with this concept. The rotation vector represents the orientation error, and the translation vector represents the localization error of the cylinder in the coordinate system $\left(\mathrm{O}, \mathrm{e}_{1}, \mathrm{e}_{2}, \mathrm{e}_{3}\right)$.

\section{Tolerancing Method by Functional Group}

Surface errors are considered independent from one another. The errors of the elementary surfaces are computed parameters in the local coordinate system. In a second phase, the surface 


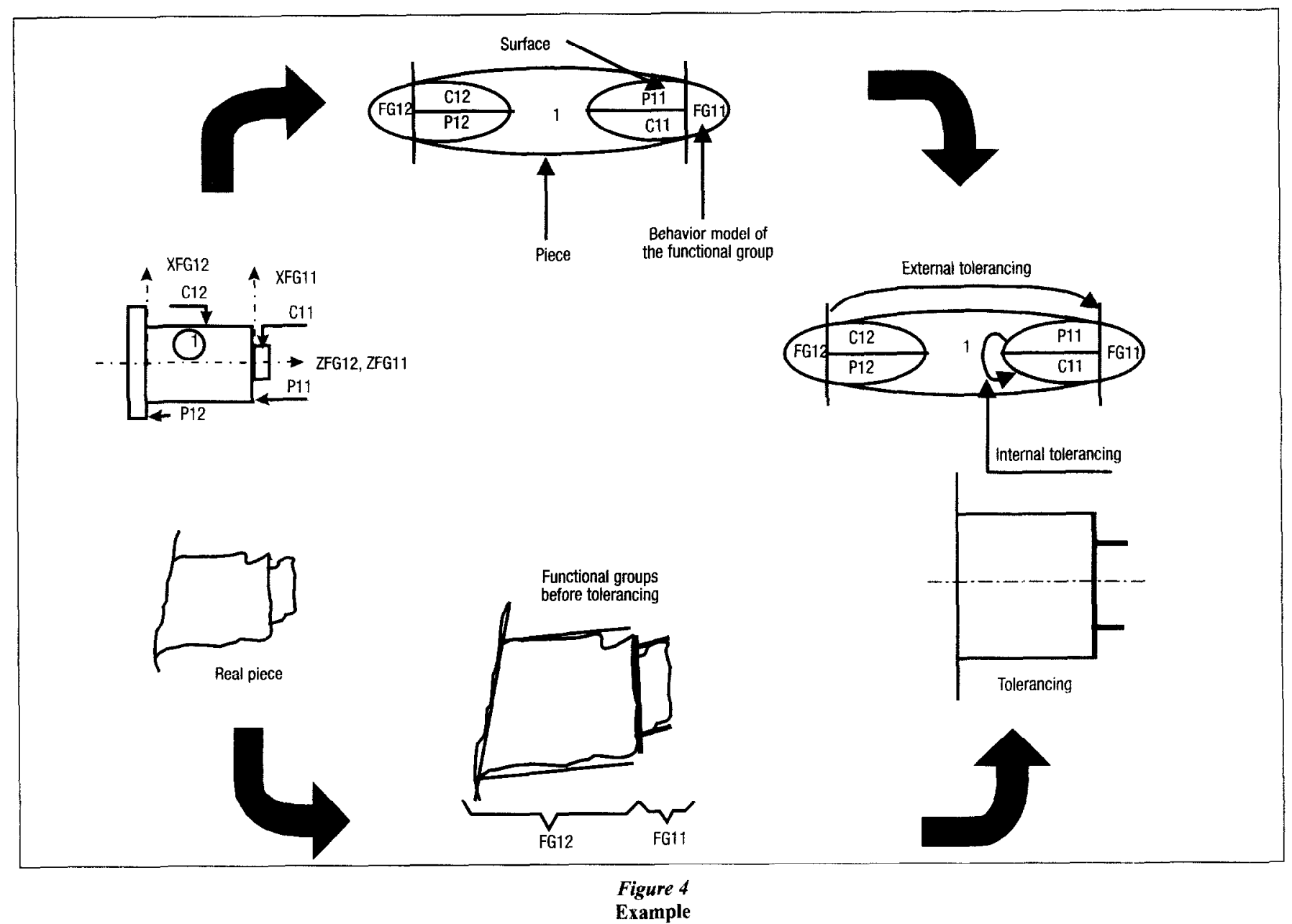

errors are written in the coordinate system of the functional group (Figure 3).

To explain the tolerancing methodology, refer to the example of Figure 4 in which the tolerancing of the surface groups (P11, C11) and $(\mathrm{C} 12, \mathrm{P} 12)$ is proposed. The $(\mathrm{C} 12, \mathrm{P} 12)$ group is the datum. The part and the two surface groups are represented by the graphic format of the functional group. The behavior model of the functional group represents the interface of the surface group, which is in contact with another part.

\section{Modeling of Internal Behavior of Functional Group}

Principle

To carry out the tolerancing of a geometric element correctly, it is necessary to take into account only six errors (three rotations and three translations). Several hypotheses are considered:

- The errors of the surface (flatness...) are negligible in comparison with other geometric errors (1),

- The parts are rigid.

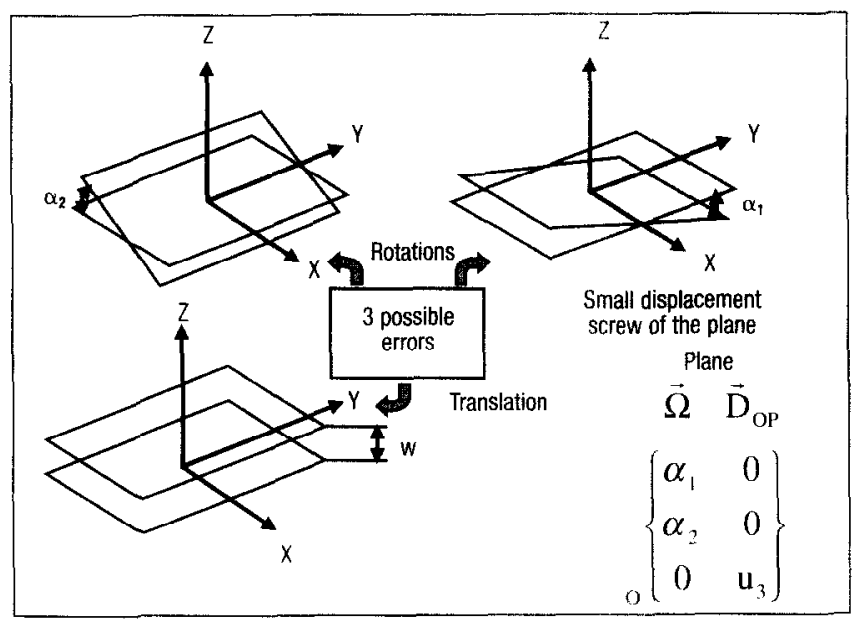

Figure 5

Plane Small Displacement Screw

The mathematical tool used to model errors is the SDS (Requicha 1983) (see Figure 5).

In the example, the two functional groups are composed of a plane and a cylinder. The error number is $7(4+3)$ whereas the mechanical joint can only accept five errors (see Figure 6). Therefore, several errors should be simultaneously limited ( 2 errors). 


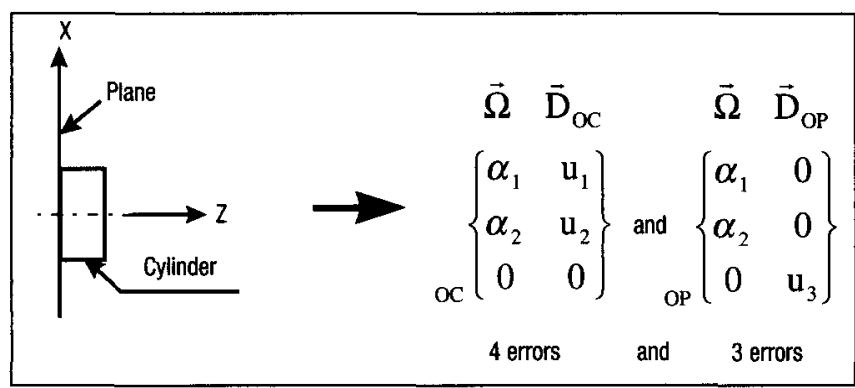

Figure 6

Case of Cylinder/Plane Functional Group

That means there are five parameters of external tolerancing and two parameters of internal tolerancing in this functional group. This tolerancing is minimal and sufficient. Surfaces of a same functional group can be divided into three classes according to their function in the mechanical joint:

- Principal surface: it guides and imposes the orientation and principal position of the functional groups.

- Secondary surface: it completes the localization and the orientation between the two functional groups.

- Unspecified surfaces: they usually contribute to the assembly of the different parts.

In the case where the functional group is composed of a plane and an orthogonal cylinder, two different issues can be considered according to sizes and clearances, as shown in Figure 7.

(A) Plane is preponderant (Figure 8). That means:

- Length-to-diameter ratio of the cylinder is very low,

- Clearances between both parts are high.

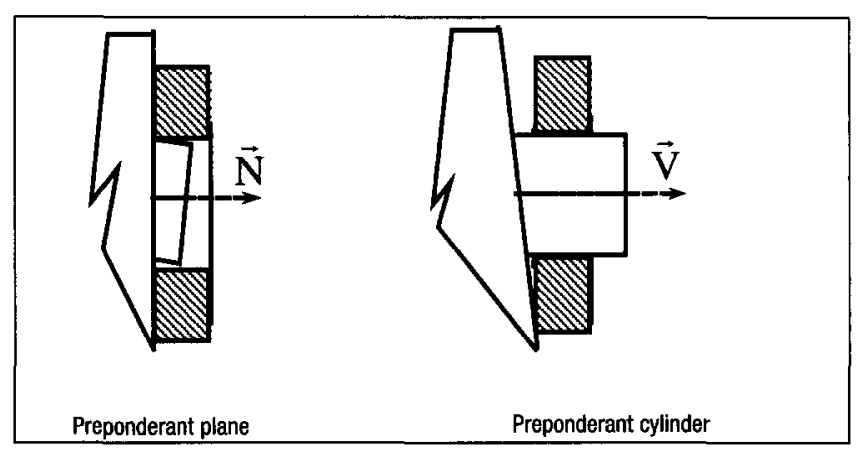

Figure 7

Principal Surface

The orientation of the part mounted on this surface group is given by the normal vector of the plane. A circle can also model the cylinder. Nevertheless, the geometric errors of the cylinder must be saved.

Translation and rotation parameters have been integrated into a composed translation parameter. Also, cylinder rotation $\alpha_{2}$ is included in $U_{1 C 11}$, and cylinder rotation $\alpha_{1}$ is included in $\mathrm{U}_{2 \mathrm{C} 11}$. When the functional group is toleranced, external tolerancing is limited to only five errors. $\alpha_{1}$ and $\alpha_{2}$ are not limited in this tolerancing; they should be limited in the internal tolerancing. Thus, the perpendicularity of cylinder $\mathrm{C} 11$ needs to be imposed in relation with plane $\mathrm{P} 11$. This requirement can be transcribed with the maximum material condition for the cylinder because the diameter of $\mathrm{C} 11$ and its orientation in relation to $\mathrm{P} 11$ have an effect on the interface between both parts. This interface screw represents the behavior of the assembly of both functional groups.

(B) Preponderant cylinder (Figure 9). That means:

- Length-to-diameter ratio of the cylinder is very large,

- Clearances between both parts are low.

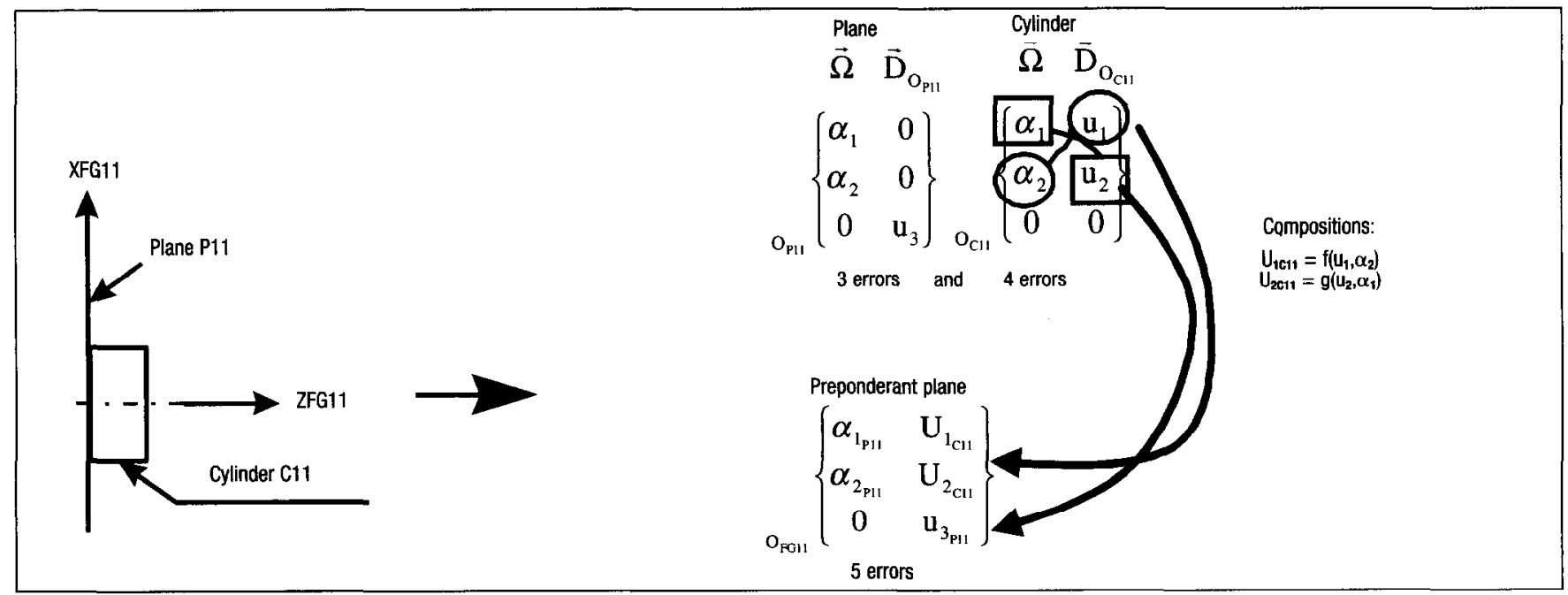




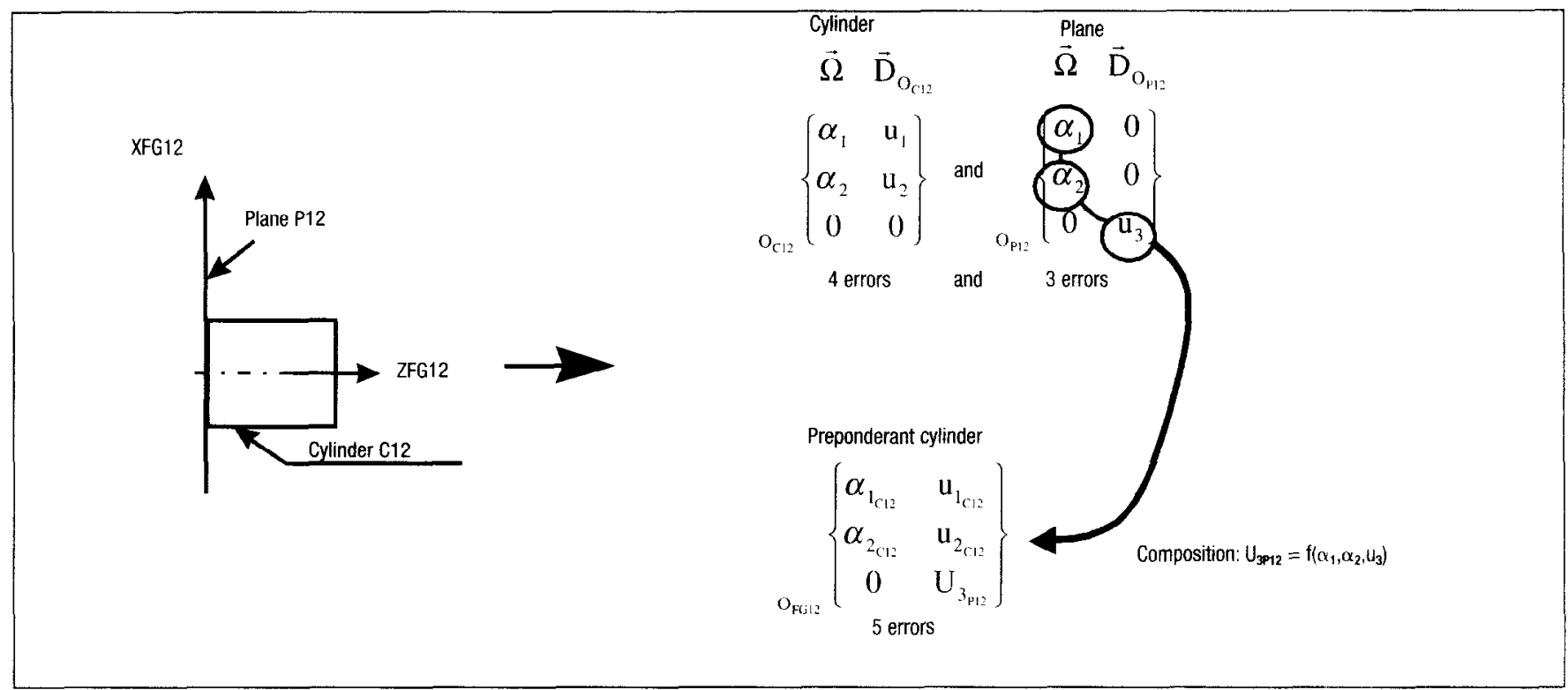

Figure 9

Preponderant Cylinder

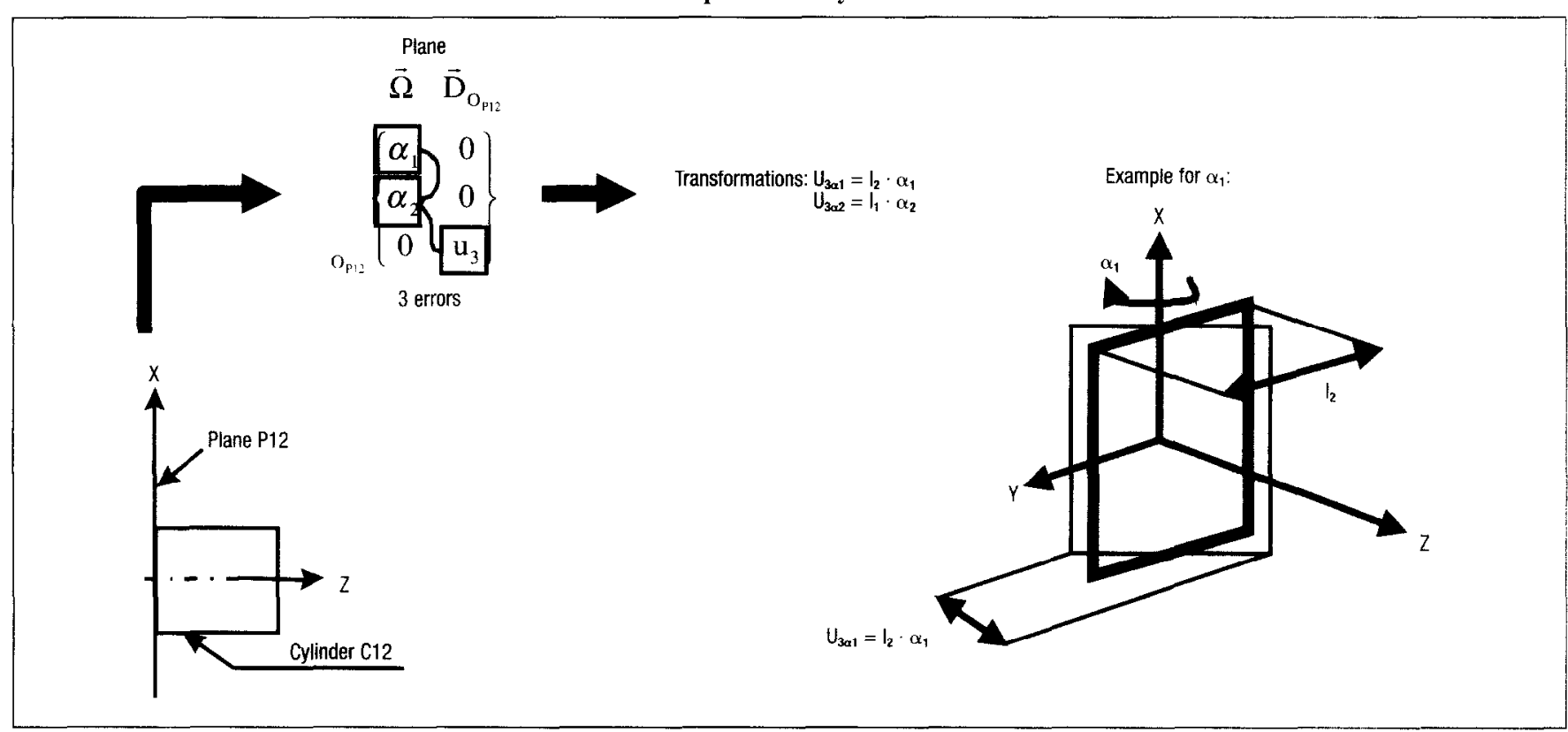

Figure 10

Transformation

The cylinder imposes the main orientation and the position of the other part $i+1$. Part $i+1$ is placed against the plane that is orthogonal to the main vector of the cylinder. Plane P12 is used as a stop to limit the translation motion of part $i+1$. Thus, plane $P 12$ can be modeled as a single contact.

Once more, a translation and two rotation parameters have been integrated in a single translation parameter. This involves limiting both rotations with tolerancing.

\section{Equations of Internal Behavior}

An intrinsic parameter is imposed for closed surfaces such as cylinders or cones (diameter for cylinder, angle for cone). This parameter has an effect on the determination of the interface model. Different transformations can be achieved to create a functional group.

(a) $\mathrm{S} 1$ error transformation (Figure 10$): \mathrm{U}_{\mathrm{i}}=$ $\alpha_{i} \cdot 1_{i}$ or $\alpha_{i}=u_{i} / 1_{i}$

Error transformation is usually made just before integration. It modifies the type of error without 


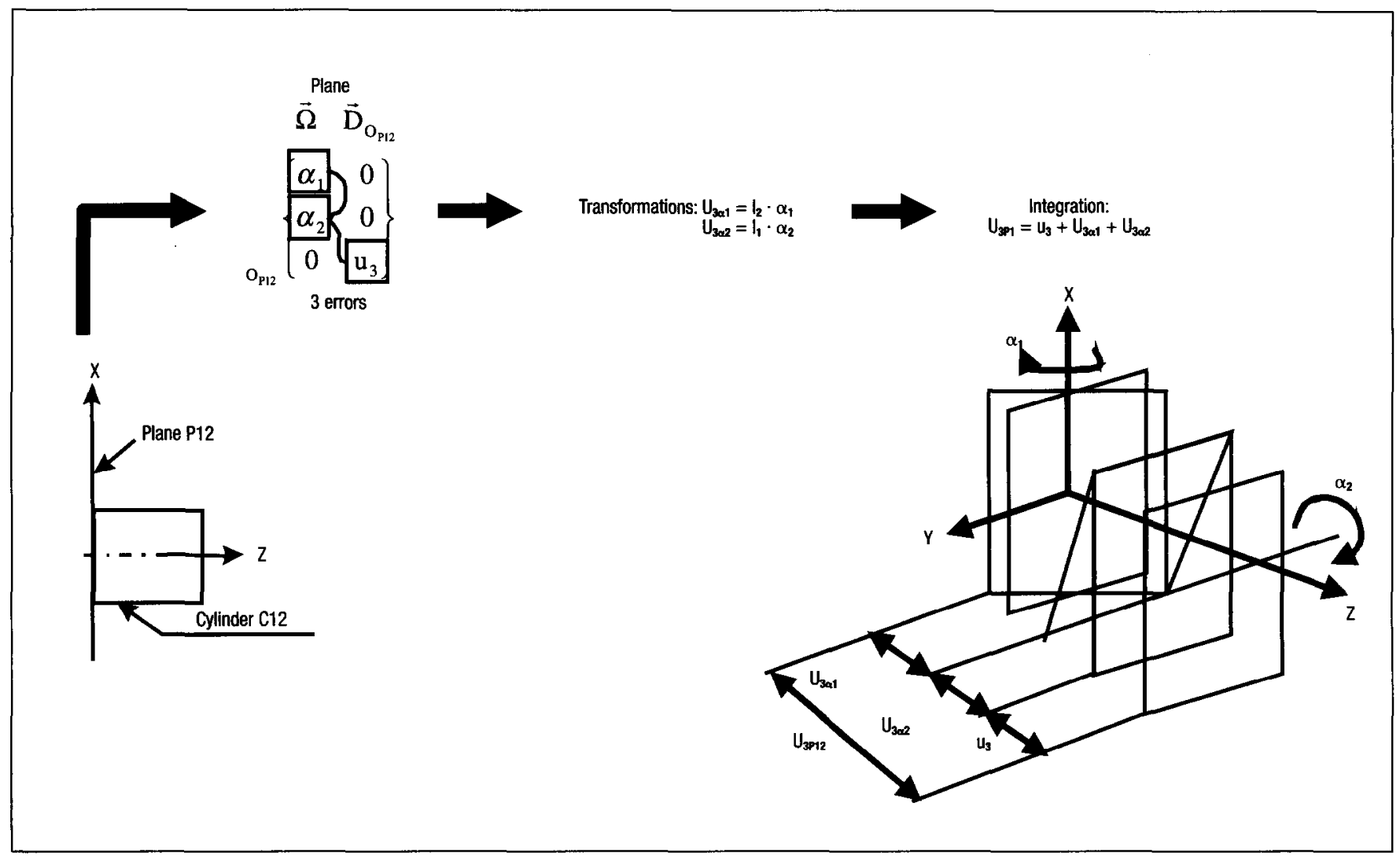

Figure 11

Integration

changing its effect. A rotation error can be transformed as a translation error and vice versa. This operation has no effect on internal tolerancing.

(b) S2 error integration (Figure 11): $\mathrm{U}_{\mathbf{k}}=\Sigma \mathrm{u}_{\mathbf{i}}$ Error integration involves from 1 to $\mathrm{N}-1$ internal specifications ( $\mathrm{N}$ is the number of integrated errors). This operation has an effect on external tolerancing and on the interface model.

(c) S3 overabundance of errors

An overabundant error of a secondary surface (in comparison with a higher level surface) must be limited through internal tolerancing.

\section{Tolerancing of Internal Behavior}

The vectorial description is used to model the surface errors. Hypothesis (1) allows writing the tolerancing based on the ISO norm (ISO1101). After having calculated the equations of the internal behavior, the geometric parameters can be identified that should specify the tolerances of the surfaces in a qualitative way.

The orientation tolerances limit the angular errors of the surface ( $\vec{\Omega}$ vector). The localization tolerances limit the position errors and the orientation errors of the surface ( $\vec{D}_{0}$ and $\vec{\Omega}$ vectors) (Figure 12).

The following symbols are used for writing the tolerancing:

$\begin{array}{ll}\text { DTM A } & \text { Datum A } \\ \text { S60K6 } & \text { Shaft with } \varnothing 60 \mathrm{~K} 6 \\ \text { ENV } & \text { Envelop requirement } \\ \text { PER } & \text { Perpendicularity } \\ \text { POS } & \text { Position } \\ \text { CAX } & \text { Coaxiality } \\ \text { PFS } & \text { Profile any surface } \\ \text { DIA } & \text { Diameter }\end{array}$

Figure 13 shows both cases detailed above (preponderant plane, preponderant cylinder). $\mathrm{U}_{1 \mathrm{Cl1}}, \mathrm{U}_{2 \mathrm{C11}}, \mathrm{U}_{3 \mathrm{P} 12}$ are defined by the equations of the internal behavior. In the functional group FG11, the orientation errors of cylinder $\mathrm{C} 11$ are limited by a perpendicularity with regard to the datum P11. In FG12, the orientation errors of plane P12 are limited by a perpendicularity with regard to datum $\mathrm{C} 12$. 


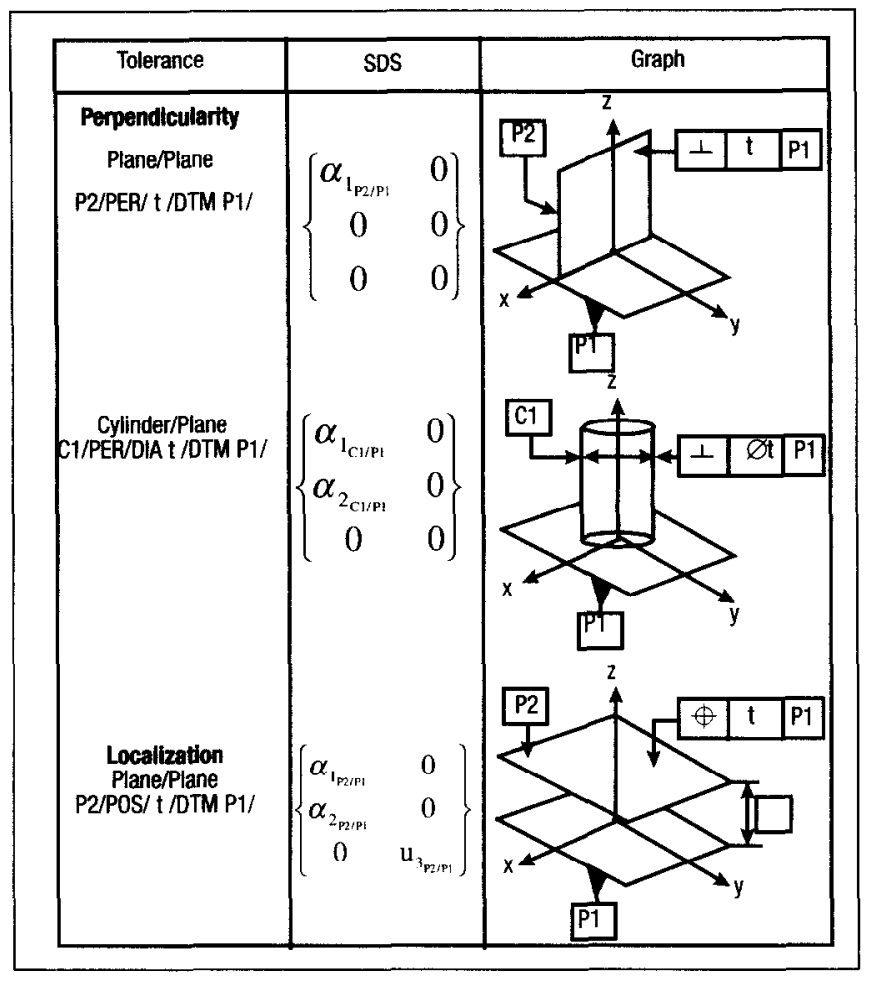

Figure 12

Tolerance Examples

\section{Modeling of Behavior of Two Functional Groups Belonging to the Same Part \\ (Figure 14)}

After modeling the internal behavior, the functional groups are created. The next step is composed of the tolerance between the two functional groups.

Tolerancing of the functional groups FGi,j in relation to $F G i, j+1$ is performed ( $i$ represents the part and $j$ the functional group). The coordinate system is placed in $\mathrm{FGi}, \mathrm{j}+1$.

Errors between both functional groups are modeled by a SDS that is composed of errors in both functional groups. An error of FGi,j can be limited only if FGi,j+1 has a reference surface in this direction. If an error of FGi,j+1 exists, that means conversely there is a surface in this direction. Figure 15 presents a summary of internal and external tolerancing based on a graphical formalism of the functional group.

\section{Modeling of Behavior of Two Functional Groups Belonging to Two Different Parts}

There are physical discontinuities in the interface composed of clearances. The orientation of assembly surfaces imposes coordinate system discontinuity (Figure 16). The SDS models the behavior of the interface. This issue is not present-

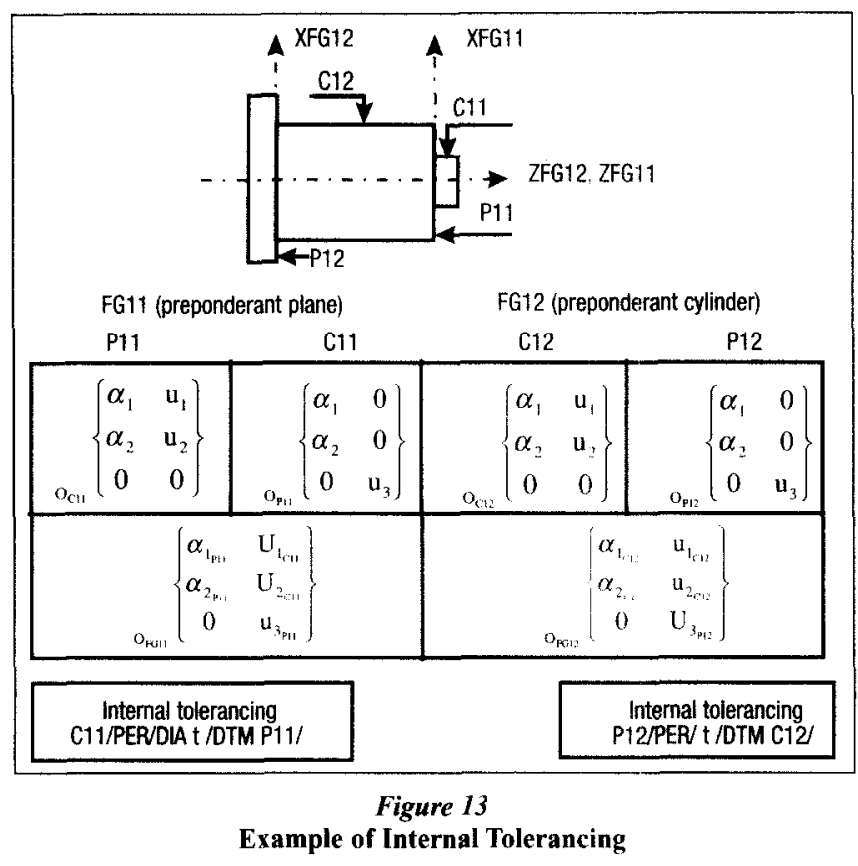

ed in this paper but is covered in Linares, Boukebbab, and Sprauel (1998).

\section{Synthesis of Tolerancing Method}

The case in study is a mechanism composed of two conic gears (Figure 17). Each gear is mounted on the frame by two ball bearings. Clearances of the ball bearing assembly are negligible. Only the position (localization and orientation) between the two pitch cones is studied.

The first step consists in studying the functional flow in the mechanism according to the graphical formalism of the functional group, as shown in Figure 18. The overall goal is to ensure a good power transmission.

Flows are studied by identifying the different contact points where mechanical power is transmitted. Note that the $\mathrm{Fl}$ flow integrates two internal loops ( $\mathrm{F} 2$ or F3) (see Figure 19). Flow F1 ensures the position of one pitch cone to the other. F2 and F3 flows represent the value of the prestress constraint to be implemented to avoid the detachment of ball bearings from the moving part in rotation. In this case, both flows F2 and F3 are identical. Ball bearings are standard elements and thus not studied.

At this level, F2 and F3 flows have to be studied. The modeling of the internal behavior of the functional group provides an internal tolerancing of the conic gears. It has no effect on the external behavior of the functional group. External tolerancing is obtained by combining two functional groups belonging to the same part: Gear 1 or 5 


\begin{tabular}{|c|c|c|}
\hline FG11 & \multicolumn{2}{|r|}{$\mathrm{FG} 12$} \\
\hline$\left\{\begin{array}{cc}\alpha_{l_{p \mid 1}} & \mathrm{U}_{\mathrm{i}_{\mathrm{cn}}} \\
\alpha_{2_{\mathrm{p} \mid 1}} & \mathrm{U}_{2_{\mathrm{c} \mid 1}} \\
0 & \mathrm{U}_{3_{\mathrm{p} \mid 1}}\end{array}\right.$ & $\mathrm{o}_{\text {Pet12 }}$ & $\left\{\begin{array}{cc}\alpha_{1_{\mathrm{c} 12}} & \mathbf{u}_{1_{\mathrm{c} 12}} \\
\alpha_{2_{\mathrm{C} 12}} & \mathrm{u}_{2_{\mathrm{c} 12}} \\
0 & \mathrm{U}_{3_{\mathrm{p}_{12}}}\end{array}\right\}$ \\
\hline & 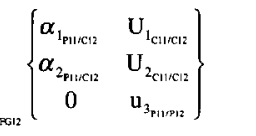 & \\
\hline $\begin{array}{l}\text { Internal tolerancing } \\
\text { C11/PER/DIA t/DTM P11/ }\end{array}$ & & $\begin{array}{l}\text { Internal tolerancing } \\
\text { P12/PER/ t /DTM C12/ }\end{array}$ \\
\hline & $\begin{array}{l}\text { External tolerancing } \\
\text { P11/PER/ / /DTM C12/ } \\
\text { P11/POS/ / /DTM/ P12/ } \\
\text { C11/CON/DIA t /DTM C12/ }\end{array}$ & \\
\hline
\end{tabular}

Figure 14

Example of External Tolerancing

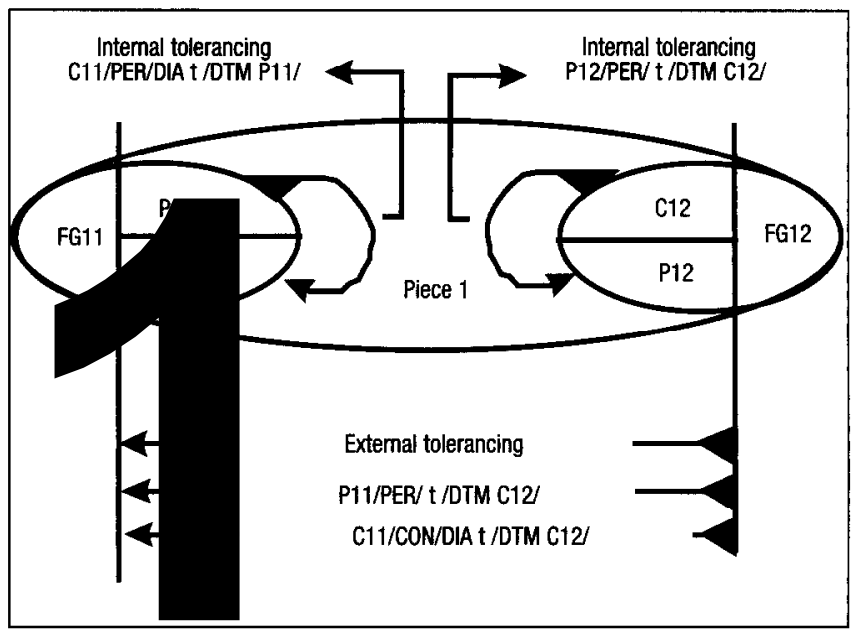

Figure 15

Summary
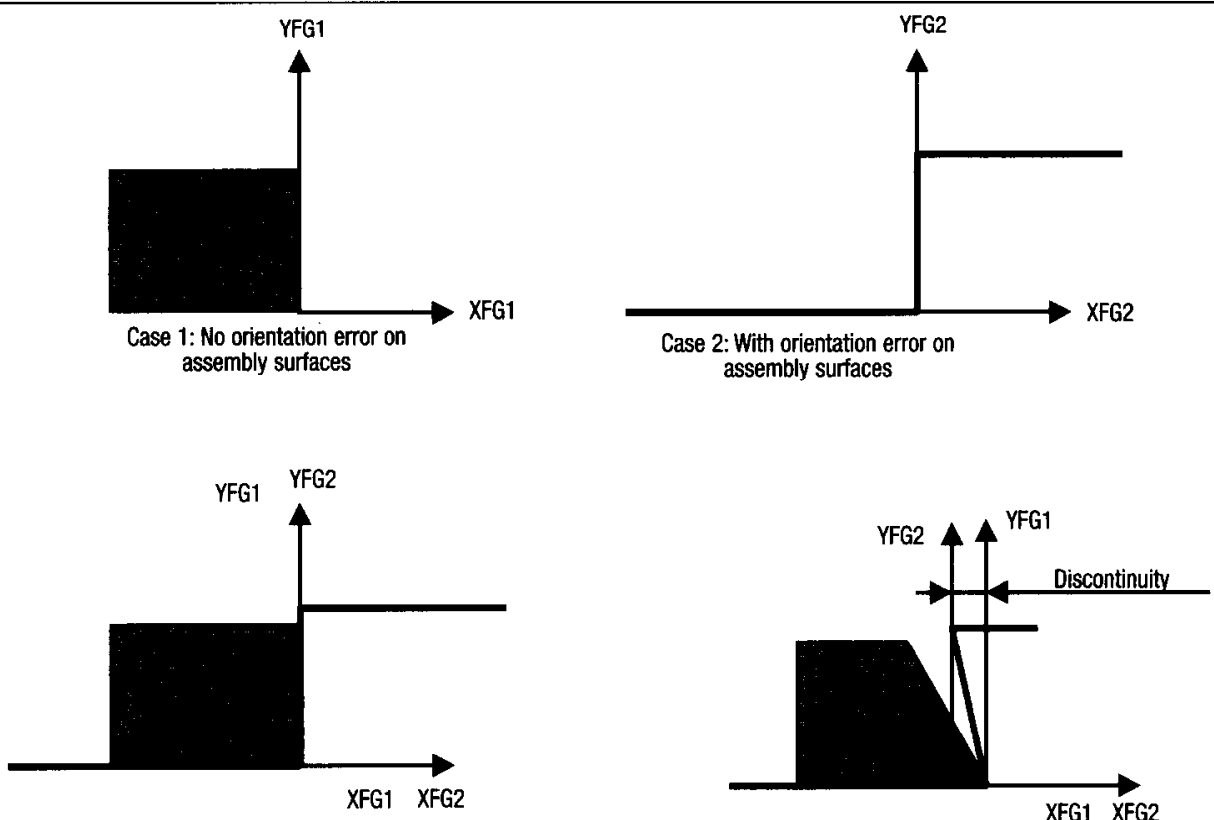

Figure 16

Coordinate System Discontinuity

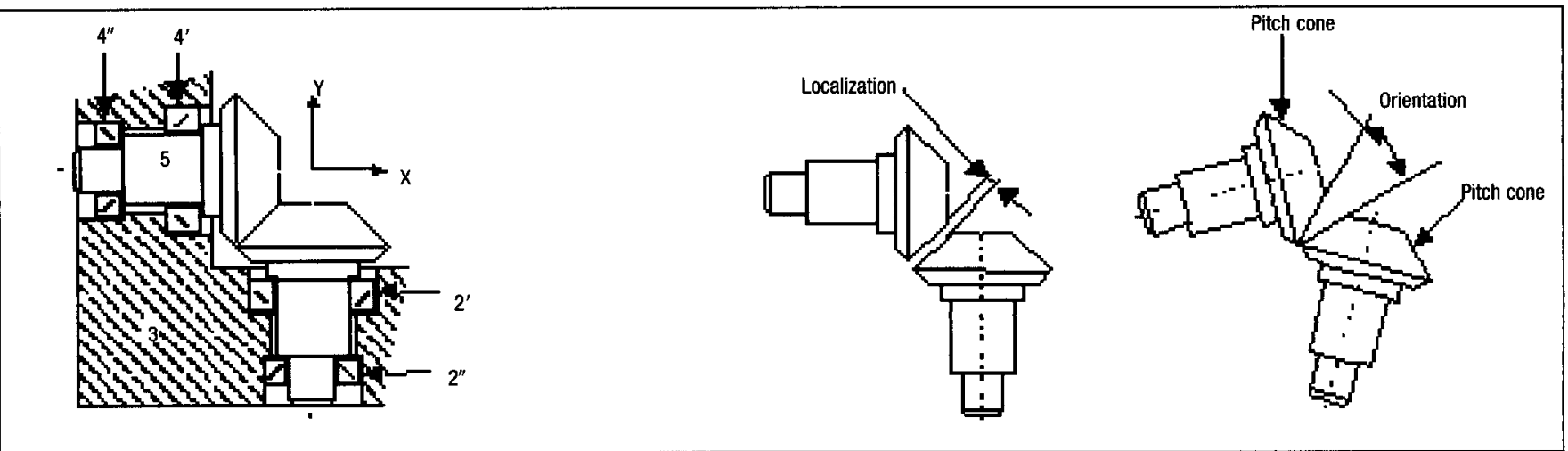

Figure 17

Example and the Functional Conditions 


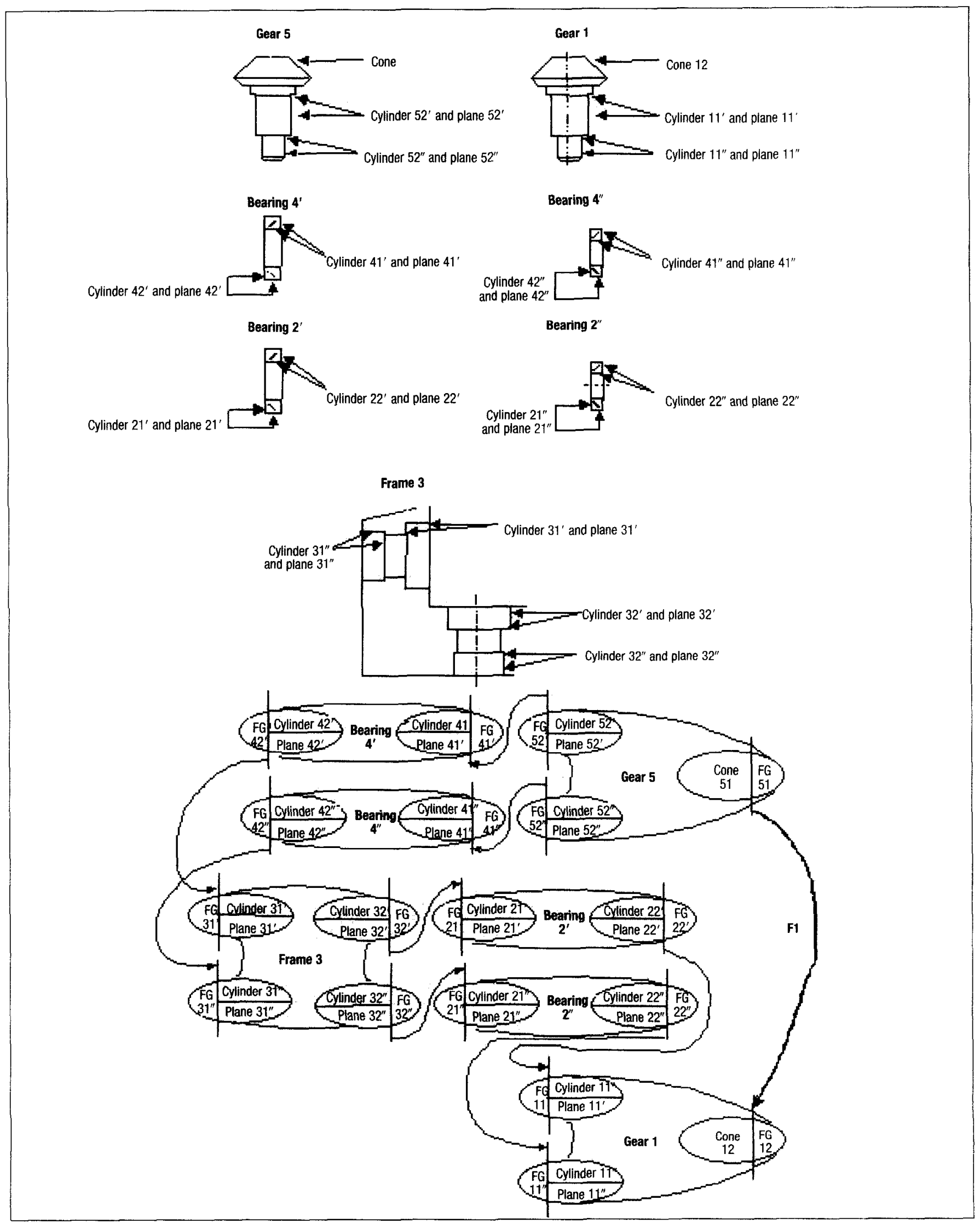

Figure 18

Surface Notations and Functional Flows 


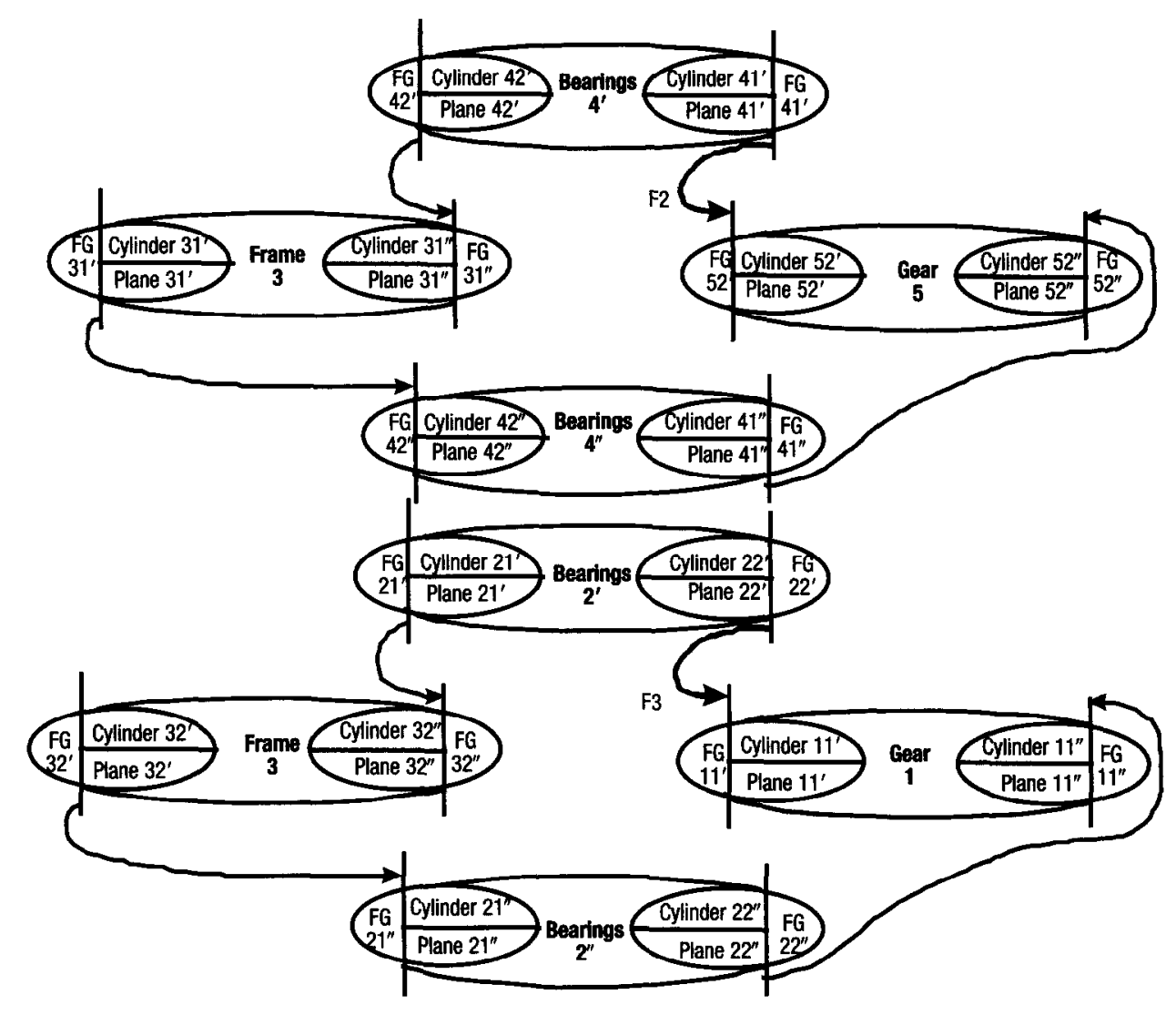

Figure 19

$F 2$ and F3 Flows

(Figure 20), Frame 3 (Figure 21). This part is placed in both flows F2 and F3. The tolcrancing of both functional groups integrated in both flows is identical:

NB: tolerancing is the same for the groups of surfaces $31^{\prime}$ and $31^{\prime \prime}$.

Processing of Flow 1: After computation of F1 and F2, the external behavior of FG52 composed of FG52' and FG52" is the result of the combination of the external behavior of FG52' and FG52". This is different from the processing of the F2 and F3 flows. The diagram in Figure 22 can also model Flow 1.

Gear (Figure 23): In this phase of study, the pitch cone of the gear should be positioned in relationship with the functional group 52 or 12 . Composition rules of both functional groups belonging to the same part are useful to carry out this tolerancing.
It is noted that it is possible to suggest another tolcrancing for the gcar using the common zone notion of norm ISO (Figure 24) without changing the functional significance of each surface. The quality of the datum surface FG52 is guaranteed by this tolerancing. This common zone notion permits the tolerancing to be simplified. The constraint between Cyl52" and Cyl52' in Figure 19 is deleted (Figure 25).

Through the same process as that used for gears, the results in Figure 26 are obtained.

\section{Conclusion}

The approach presented is based on a systematic approach. The functional group concept carries out a structured analysis of tolerancing for mechanical systems. This method avoids obtaining a very high number of requirements linked to the same function. The notion of internal hierarchy allows three single composition laws (transformation, integration, and 


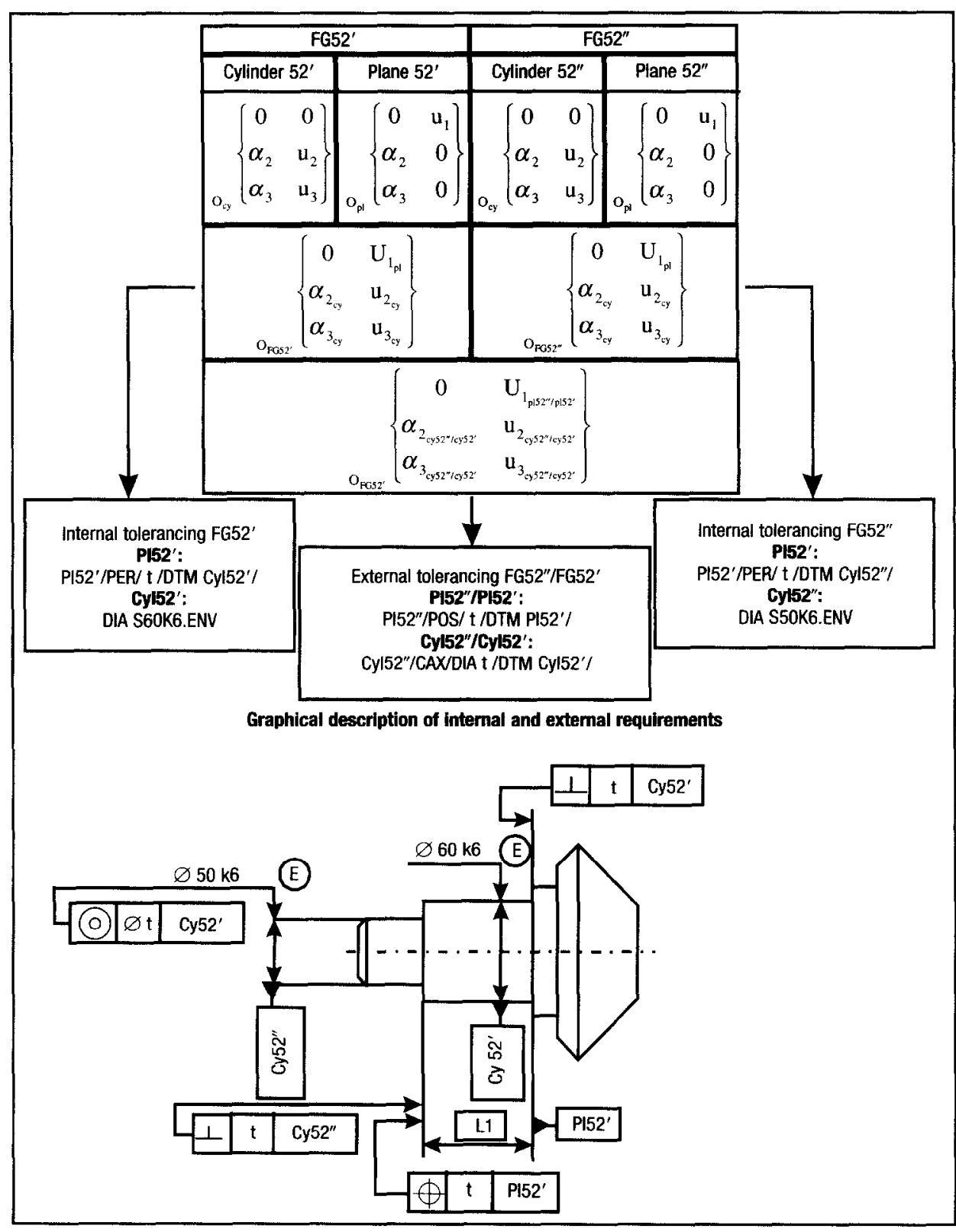

Figure 20

Tolerancing of Conic Gears Computed from the F2 or F3 Study
Theories, Standards and Application, $\mathrm{H}$. ElMaraghy, ed. Chapman \& Hall.

Bennis, F.; Pino, L.; and Fortin, C. (1999). "Analysis of positional based on the assembly virtual state." 6th CIRP Int'l Seminar on Global Consistency of Tolerances, Twente. Netherlands, March 1999, pp415-424.

Bhide, S.; Davidson, J.K.; and Shah, J.J. (2001). "Areal coordinates: The basis of a mathematical model for geometric tolerances." CIRP Int'l Seminar on Computer Aided Tolcrancing, Cachan, France, 2001, pp83-92.

Bourdet, P. and Clement, A. (1988). "A study of optimal-criteria identification based on the small displacement screw model." Annals of the CIRP (v37), pp503-506.

Clement, A.; Desrochers, A.; and Riviere, A. (1991). "Theory and practice of 3D tolerancing for assembly." 2nd CIRP Int'l Working Seminar on Tolerancing, Pennsylvania State Univ., May 1991, pp25-55.

Etesami, F. (1991). "Position tolerance verification using simulated gauging." Int'l Journal of Robotics Research (v10, n4), pp358-370.

Farmer, L.E. and Galdman, C.A. (1986). "Tolerance technology computer based analysis." Annals of the CIRP (v35/1), pp7-10.

Gaunet, D. (1993). "Vectorial tolerancing model." 3rd CIRP Seminar on Computer Aided Tolerancing. Cachan, France, April 1993, pp25-50.

Gaunet, D. (2001). "3D functional tolerancing and annotation: CATIA tools for geometrical specification." CIRP Int'] Seminar on Computer Aided Tolerancing. Cachan, rrance, 2001, pp31-39.

Giordano, M.; Duret, D.; Tichadou, S.; and Arrieux, R. (1992). "Clearance space in volumic dimensionning." Annals of the CIRP (v41/1).

Kethara, T.M. and Wilhelm, R.G. (2001). "Curves for profile tolerance zone boundaries." CIRP Int'l Seminar on Computer Aided Tolerancing, Cachan. France, 2001, pp275-283.

Linares, J.M.; Boukebbab, S.; and Sprauel, J.M. (1998). "Co-operative engineering approach: Tolerancing, control." CIRP semi

nar, Production Technology Center, Berlin, 1998, pp145-156.

overabundance) to be implemented. These operations provide an internal organization of the different surfaces according to their participation in performing the function. This method can also generate equations that characterize the interface between two functional groups.

This method allows the designer to write the tolerance of parts in several ways. Moreover, this method is now being extended to take into account systems with clearances in interfaces.

\section{References}

Ballot, E. and Bourdet, P. (1998). "A computational method for the consequences of geometrical errors in mechanisms." In Geometric Tolerancing:
Liu, J. and Wilhelm, R. (2001). "Genetic algorithms for TTRS tolerance analysis." CIRP Int'l Seminar on Computer Aided Tolerancing. Cachan. France, 2001, pp55-64.

Parametric Technology Corp. (1994). "Pro/ENGINEER: Interface guidc." Waltham, MA.

Requicha, A.G. (1983). "Toward a theory of geometric tolerancing." Int'l Journal of Robotics Research (v25, n4), pp45-60).

Rivest, L.; Fortin, C.; and Morel, C. (1994). "Tolerancing a solid model with a kinematic formulation." Computer Aided Design (v26, n6). pp465-485.

Sacks, E. and Joskowicz, L. (1997). "Parametric kinematic tolerance analysis of planar mechanisms." Computer Aided Design (v29, n5), pp333-342.

Sangho, P. and Kunwon, L. (1998). "Verification of assemblahility between toleranced parts." Int'l Journal of Computer Aided Design (v30, n2), pp95-104. 
Srinivasan, V. (1993). "Recent efforts in mathematization of ASME/ANSI Y14.5M standard." 3rd CIRP Seminar on Computer Aided Tolerancing, Cachan, France, April 1993, pp223-232.

Teissandier, D.; Couetard, Y.; and Gerard, A. (1997). "Three dimensional functional tolerancing with proportioned assemblies clearance volume: Application to setup planning." 5th CIRP Seminar on Computer Aided Tolerancing, Toronto, 1997, pp113-124.

Teissandier, D.; Delos, V.; and Couetard, Y. (1999). "Operations on polytopes: Application to tolerance analysis." Proc. of 6th CIRP Int'1 Seminar on Global Consistency of Tolerances, Twente, Netherlands, March 1999, pp425-434.

Turner, J.U. (1993). "A feasibility space approach for automated tolerancing." Journal of Engg. for Industry (v115), pp341-346.

Wayne, T. and Hanson, E.G. (1984). "Otfset of two dimensional profiles." IEEE CG\&1, pp36-46.

Wirtz, A. (1991). "Vectorial tolerancing for production quality control." 2nd CIRP Int'l Working Seminar on Tolerancing, Pennsylvania State Univ., May 1991, pp77-84.

\section{Authors' Biographies}

Dr. Jean Marc Linares studied manufacturing technology at the Ecole Normale Supérieure de Cachan, earning a $\mathrm{PhD}$ in 1996. He works in the EA(MS) ${ }^{2}$ Laboratory at the Université de la Méditerranée in Aix-en-Provence. His research interests include tolerancing, coordinate measuring machincs, and uncertainty of measurement.

Dr. Cédric Anthierens received his $\mathrm{PhD}$ in 1999 at the Institut National des Sciences Appliquées de Lyon. His current affiliation is with CESTI Toulon, and his research interests include automationand robotics.

Prof. Dr.Ing. Jean Michel Sprauel studied mechanics at the Ecole Nationale Supérieure des Arts et Métiers. He received his $\mathrm{PhD}$ in 1980 and has been a professor since 1991 . He is responsible for the EA(MS) Laboratory at the Université de la Méditerranée in Aix-en-Provence. His research interests include X-rays, residual constraints, mechanical behavior, and mechanics.

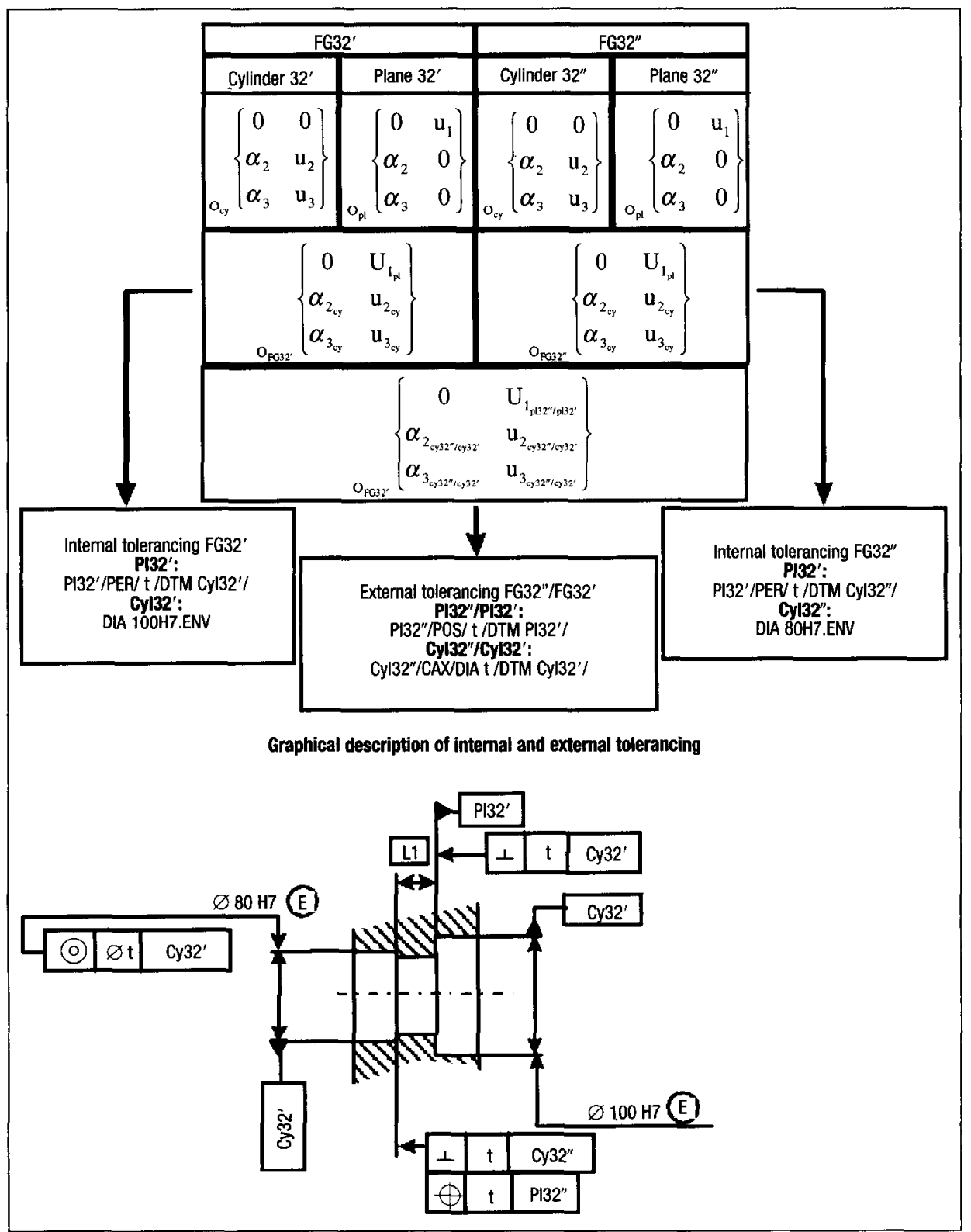

Figure 21 


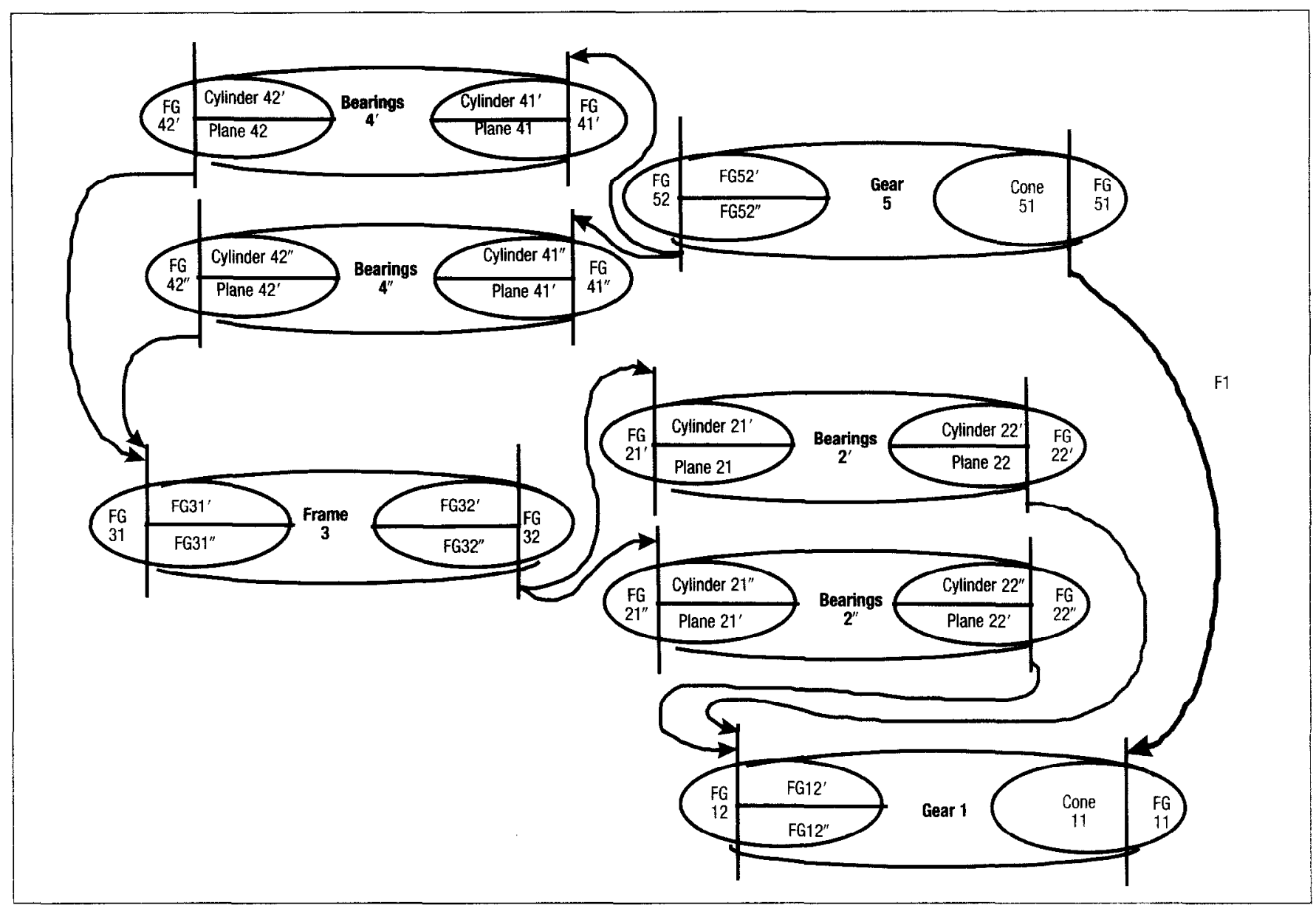

Figure 22

Flow 1 After Processing of $F 2$ and $F 3$ 


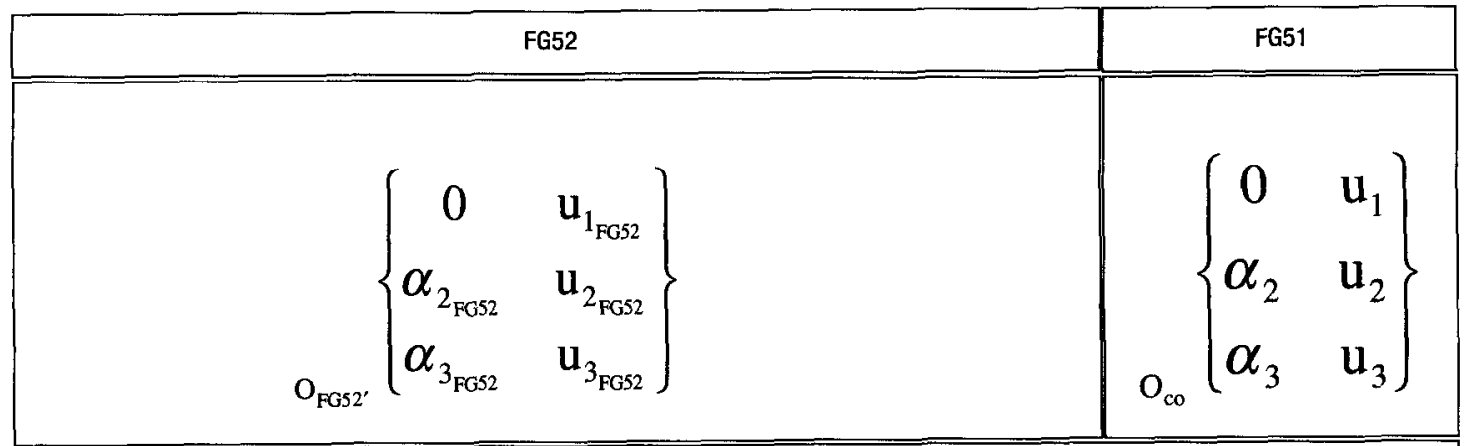

$\left\{\begin{array}{cc}0 & \mathrm{u}_{\mathrm{I}_{\mathrm{co} / \mathrm{FGS} 2}} \\ \alpha_{2_{\mathrm{co} / \mathrm{FGS} 2}} & \mathrm{u}_{2_{\mathrm{co} / \mathrm{FG} 2}} \\ \alpha_{3_{\mathrm{co} / \mathrm{FG} 52}} & \mathrm{u}_{3_{\mathrm{co} / \mathrm{FS} 2}}\end{array}\right\}$

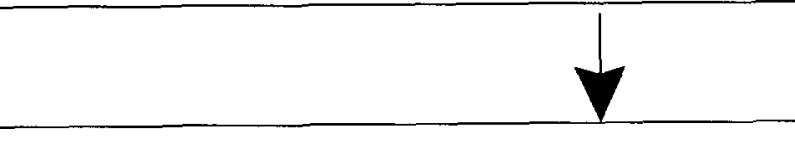

External tolerancing FG51/FG52 Co51/PFS/ t /DTM (Cyl52' - Cyl52')DTM PI52'

Graphical description of external tolerancing

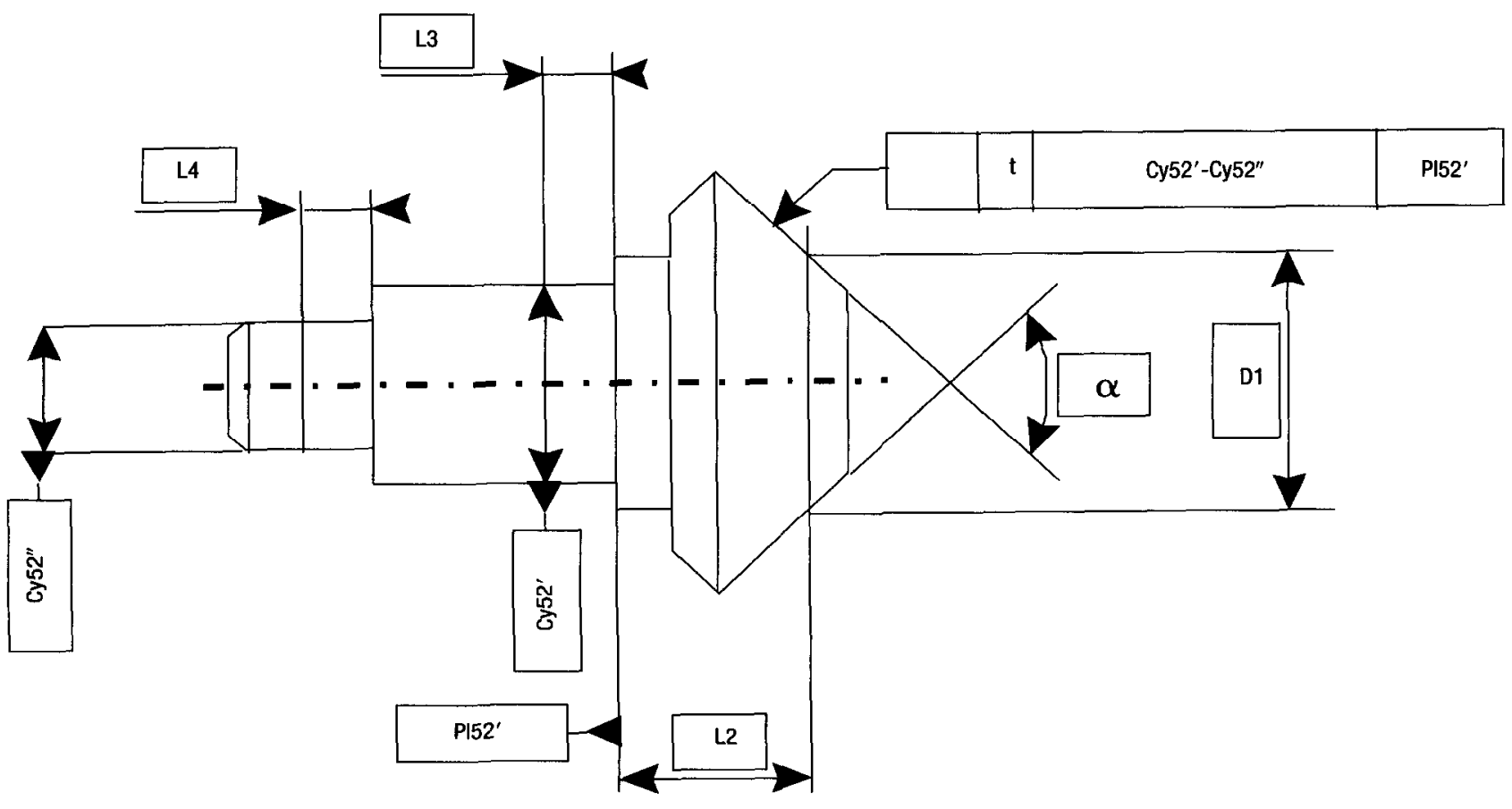



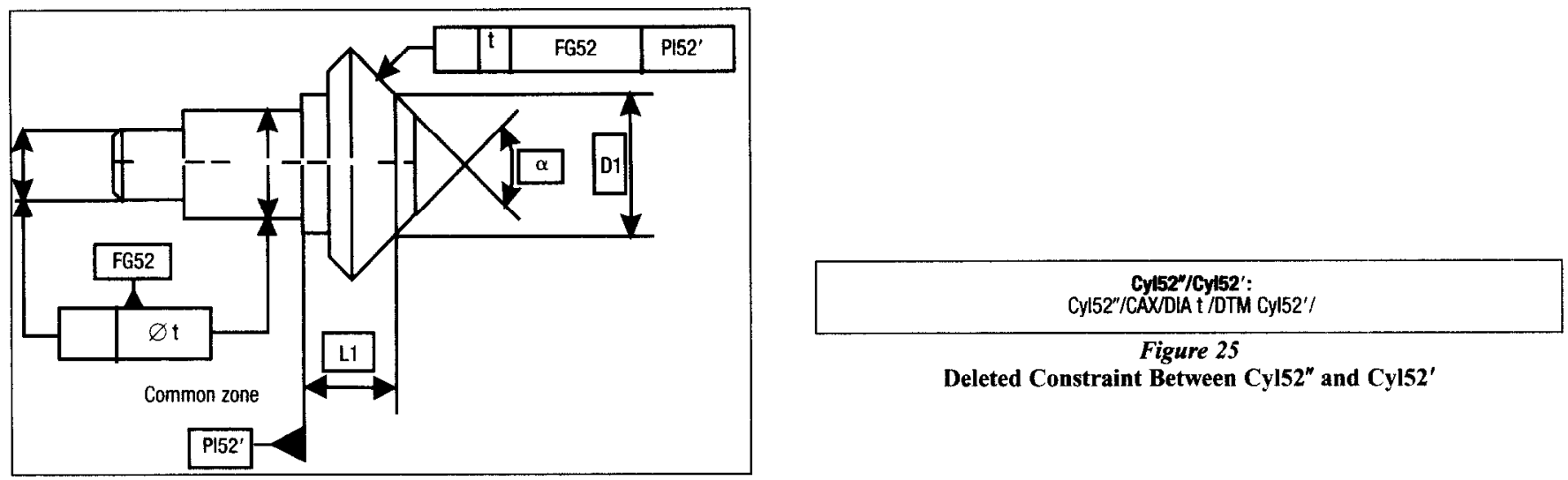

Figure 25

Deleted Constraint Between Cyl52" and Cyl52'

Figure 24

Second Tolerancing of Pitch Cone

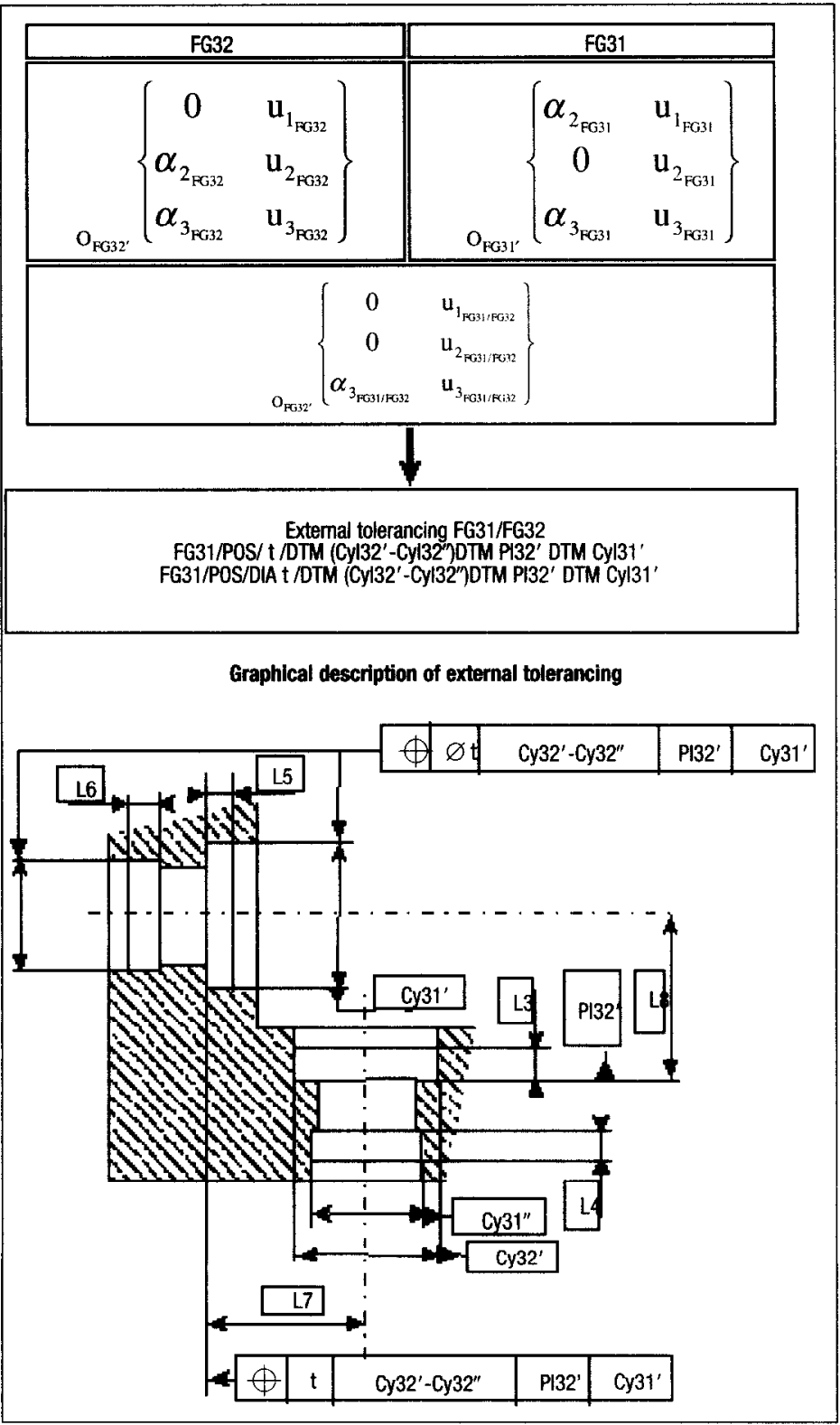

Figure 26

External Tolerancing Provided by F1 Flow 